TWO CASES OF

\title{
OSTEOSARCOMA OF THE THIGH BONE,
}

\author{
REQUIRING AMPUTATION OF THE LIMB IN \\ BOTH INSTANCES.
}

By R. A. FROGLEY, EsQ., of Hounstow.

Communicated by SAMUEL LANE, Esq.

READ MARCH 28TH, 1843.

CASE I.

$\mathrm{M}-\mathrm{P}-$ _ a young female, æt. 26, of apparently healthy constitution, was the subject of a tumour of an enormous growth, evidently connected with the thigh bone. The tumour was not of an osseous hardness, but appeared to the touch to be composed partiy of solid, partly of fluid substance. It extended from the knee joint to within an inch of the trochanters, and measured, in its greatest circumference, $35 \frac{1}{2}$ inches. Its principal projection was inwards; its growth outwards appeared to have been restrained, in some degree, by the fascia lata; the tumour might be felt, however, to extend all around the femur. On the posterior aspect of the limb the increase upwards was not so great : the hand might be placed between 
the tuberosity of the ischium and the tumour. The integument covering the tumour was free from discoloration, and appeared in other respects healthy. A few enlarged veins were apparent on the surface. Progression was but little impeded, except by the weight and bulk of the limb; the leg and foot had been free from œdema, until a short period previous to the operation. The patella might be felt moveable at the lower part of the tumour, a little to the outside of the median line, and the knee might still be partly flexed. 'The patient had suffered but little pain or inconvenience at any period during the growth of the tumour. The first intimation of this formidable disease (which could not be traced to any injury) occurred in the summer of 1829 , when the patient was attacked (while taking a long walk) with rather severe pain over the inner condyle of the femur. This, however, readily gave way to rest and remedies, but returned upon any unusual exertion. It was not however till May of the following year that any swelling was perceptible, and in June she came to town to consult Mr. Lawrence. At this period a tumefaction was perceptible just above the inner condyle, projecting but little, and of the size of the half-closed hand. Mr. Lawrence gave no hopes of relief from remedies.

I did not see the patient till about the middle of February 1833. She had been previously under the care of Messrs. Tothill and Huntly, who tried various remedies, both local and constitutional: the tumour, however, had progressively increased, and 
at the time of my first visit had attained about half its ultimate size, occupying the lower half of the thigh. I recommended the immediate removal of the limb, explaining fully the increase of danger from further extension of the disease upwards. It was not, however, till the following year, that the patient could make up her mind to submit to an operation of so formidable a nature.

In the latter part of February 1834, the rapid increase of the tumour upwards, accompanied by œdema of the leg, and other symptoms of imperfect circulation, rendered it necessary to explain to the patient that no further delay could be admitted if any endeavour to save her life was to be made.

The patient at length consented, and on Saturday, March the 1st, I performed the operation in the presence of Messrs. Walker, Lane, Huntly, Emmott, Patten, and Ridout. The extent to which the disease had increased towards Poupart's ligament, gave rise to the important question whether suffcient sound bone remained to allow of the removal of the limb below the trochanters, or whether it would be necessary to disarticulate at the hip joint.

It was determined, however, to make the incision so as to provide for all emergencies.

The external iliac artery being compressed above Poupart's ligament by Mr. Lane, a long narrowbladed knife was passed through the limb from before backwards, entering about two inches below Poupart's ligament, and about an inch to the outside 
of the femoral vessels. The instrument having touched the bone, was passed on its inside, and made to pierce the limb directly opposite to the point of entrance; the inner flap was then cut, by dividing the soft parts obliquely downwards, and towards the surface. The bone was now fortunately found healthy for at least an inch below the trochanters, and the after steps of the operation were conducted accordingly. The knife was again brought to the upper part of the wound, and passed a second time from before backwards, between the remaining soft parts and the bone, and thus an outer flap was formed, by cutting obliquely downwards and outwards. In doing this, some little difficulty was experienced, from the force required to cut through so large a mass of flesh with one stroke of the knife, which, indeed, scarcely appeared strong enough for the purpose; the bone was now more completely exposed, by a scalpel applied to the muscles immediately connected with it, and was sawn through just below the trochanter minor. There was scarcely any arterial hæmorrhage. What little occurred, was immediately arrested by one of the gentlemen present grasping the flap, so as to compress the bleeding vessels, until as many as ten ligatures were applied.

The patient, who bore the operation extremely well, now became faint; two or three terrific gasps followed, and she appeared to all present in articulo mortis. She was carried immediately to bed, when, to the great satisfaction and relief of all present, she 
began to revive. The dressing of the wound was proceeded with; the flaps adapted well to each other, and were held together by four sutures and adhesive straps. A bandage could not be well adjusted, and was therefore dispensed with.

The daily symptoms of the case, as they occurred, were of extreme interest to those in attendance, but it will only be necessary here to state, that the patient went on progressively improving, until about the 28th of May, when she ceased to require any further attendance, being perfectly well.

It may be as well, however, to mention, that secondary hæmorrhage occurred about five hours after the operation, which required the wound to be opened. On dressing again, sutures were not used, and there was scarcely any union by the first intention. The ligatures were rather longer than usual in separating : that placed on the main artery did not come away before the fifth week. An erratic, indistinct kind of erysipelas appeared on the second week, occupying the opposite limb, and lingering for about a fortnight. One or two attacks, also, of vomiting and diarrhœa occurred, creating much anxiety ; they, however, gave way readily to appropriate remedies. An opiate was required every night for the first six weeks, and was then gradually dispensed with. Colocynth, rhubarb, and blue pill, were given almost daily, to ensure proper alvine secretions; and bark was had recourse to after the second week on the appearance of the erysipelas.

A cast of the limb was taken after removal, and 
afterwards a longitudinal incision made through the centre of the tumour, thigh bone and patella. The muscles could be all distinguished, the fibres of the crureus were in immediate contact with the diseased structure, the arteries and nerves all appeared healthy though much displaced, particularly in the popliteal space. The outline of the bone was exceedingly distinct, passing through the centre of the tumour, and even the medullary cavity appeared but little altered. The bulk of the tumour was made up of numerous cartilaginous cysts, many of which communicated with each other, so as to form a large central cavity, in which was contained several pints of a tenacious, yellow, honey-like fluid. The wall of the cysts being about a quarter of . an inch in thickness, was composed of a whitish elastic tissue resembling cartilage, but rather more transparent: there was very little deposit of osseous tissue, and the morbid growth appeared more connected with the periosteum, than with the bone itself. For the space of two or three inches the medullary canal was filled with a similar transparent structure. Nothing resembling the different species of malignant growth could be detected in any part of the tumour. The knee joint was perfectly healthy as to the different structures entering into its composition, being altered only in form. An engraving of a section of the tumour in its recent state, and a cast of the limb after removal, will be seen in Plate III. 
$\mathrm{E}-\mathrm{G}-$, a married lady, æt. 37, the mother of seven children, of a spare habit, and of apparently healthy constitution, states that eleven years back she first observed a small projection, about the size of half a walnut, situated on the inside of her knee, unaccompanied by any pain or tenderness, and which increased but little in size for the first five or six years. At this period I first saw the patient, and found a tumour not larger than half a bantam's egg, connected with the inner condyle of the femur, occasioning no pain or inconvenience. I recommended nothing to be done for it unless it increased in growth, or became painful:

At the expiration of another five years, viz. in March 1841, the tumour had considerably increased in size, still unattended by much inconvenience. It measured, at this time, $16 \frac{1}{4}$ inches in circumference, the measurement of the limb below the knee not exceeding 12 inches. The tumour had extended especially upwards; it was most prominent inwards and towards the ham, less so towards the outside of the knee.

At this stage of the growth of the tumour, $\mathrm{Mr}$. Lawrence was consulted, April 1st, 1841, who gave no hope of relief except in amputation of the limb. A few days after this, I was applied to again by the patient, and without knowing that Mr. Lawrence had seen the case, gave the same opinion as to the 
necessity of the removal of the limb; but the patient being at this time in the fourth month of pregnancy, I advised the postponement of the operation till after her confinement. This took place September 19, 1841.

During, and after her pregnancy, the tumour was occasionally painful for a week or a fortnight together, but the pain readily subsided under rest and the application of cold lotions. For six months previous to the performance of the operation, and particularly after weaning her child, the tumour grew more rapidly, and she suffered more pain and inconvenience from it than at any former period.

In April 1842, Dr. Chambers's opinion was taken as to the state of the patient's general health, when he informed her that no disease existed that ought to prevent the performance of the operation. Accordingly, having recruited her health by a residence in the country for a few weeks, and after some little further delay, the operation was performed August 10, 1842, in the presence of Mr. Lane, Mr. Patten, Mr. Ridout, and Mr. Sannemann, who kindly rendered me their assistance.

The circular operation was performed; the stump healed by the first intention; the ligatures came away in about three weeks, and in a month she was perfectly well, and has remained so to the present time.

The circumference of the tumour was found to measure $20 \frac{1}{2}$ inches, while that of the limb below does not exceed 12 inches, A longitudinal section 
through the centre of the thigh bone and the tumour, showed a complete identity of structure in this and the tumour of the former case, as well as a remarkable similarity in their position and general outline. The same nodulated appearance on the surface-the same transparent and cartilage-like texture-a similar displacement of the popliteal vessels, are conspicuous in both.

In each, a central cavity existed, but of less relative capacity in the smaller tumour, and the fluid contained in this was not yellow, but colourless, and not more than an ounce or two in quantity. On comparing together casts taken from the two limbs, a great resemblance may be remarked in the form and general appearance of the tumours. In both, the advancement of the growth has been upwards on the thigh, being restrained towards the leg by the insertion of the ham-string muscles-in each the most prominent part of the tumour is inwards, where a longitudinal constriction may be noticed, formed by the sartorius muscle-each presents a remarkable flatness on the outside of the limb, in which situation the tumour has been evidently compressed by the tense and unyielding fascia lata of this part, while in the loose texture of the popliteal space a considerable projection appears. I am happy, in conclusion, to be able to mention the more fortunate coincidence of the recovery of both patients from the operation-their entire freedom from any return of the disease - and their enjoyment at the present moment of perfect health. 
$\therefore \quad \therefore \therefore ?$

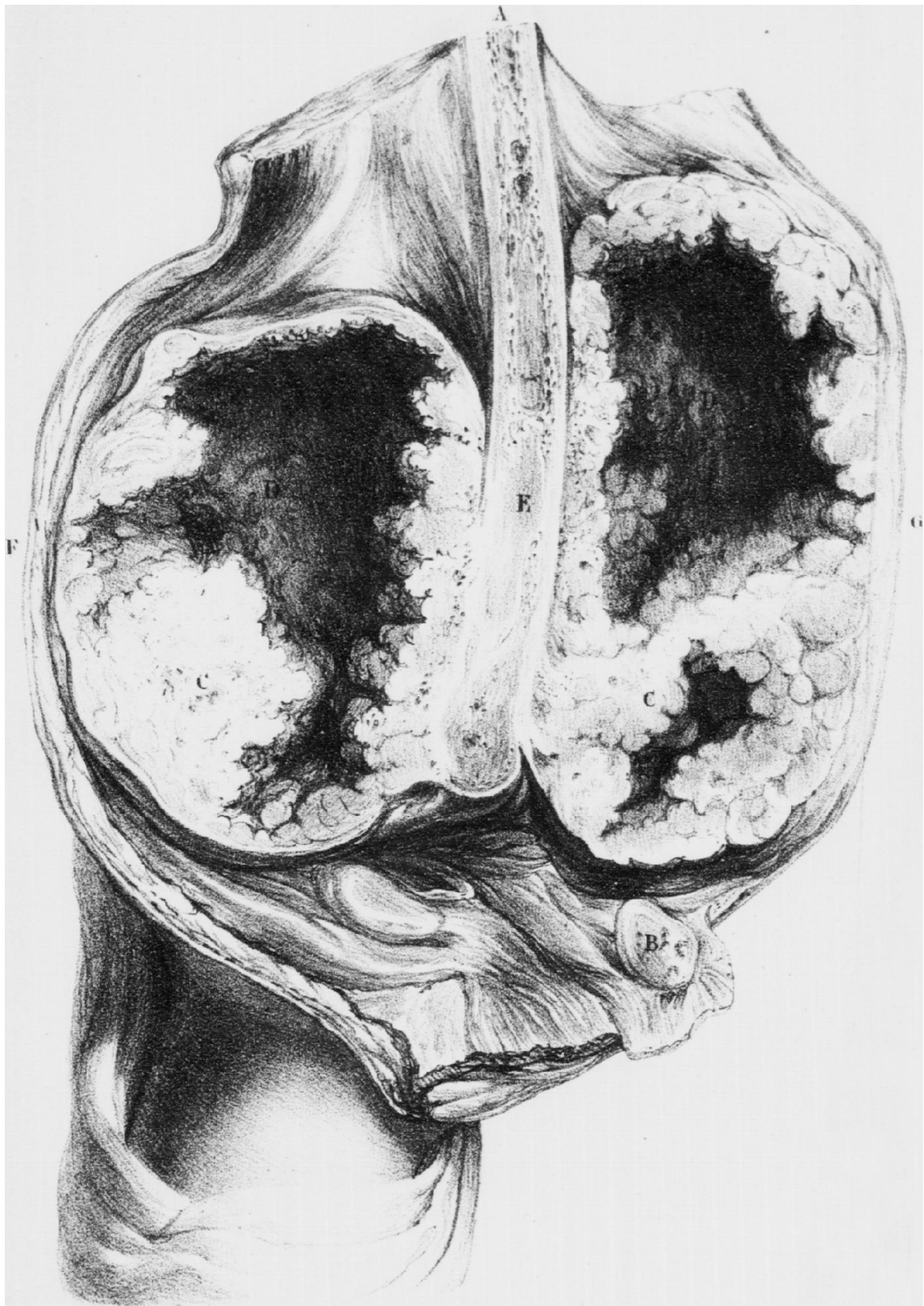
A. Antores:
B. Prella
C. eteclisin or the Firmom:

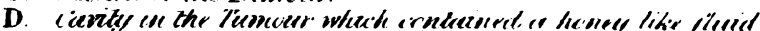

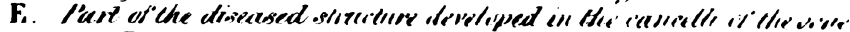 Diameder thom $F$ is of 11,4 inckes. 


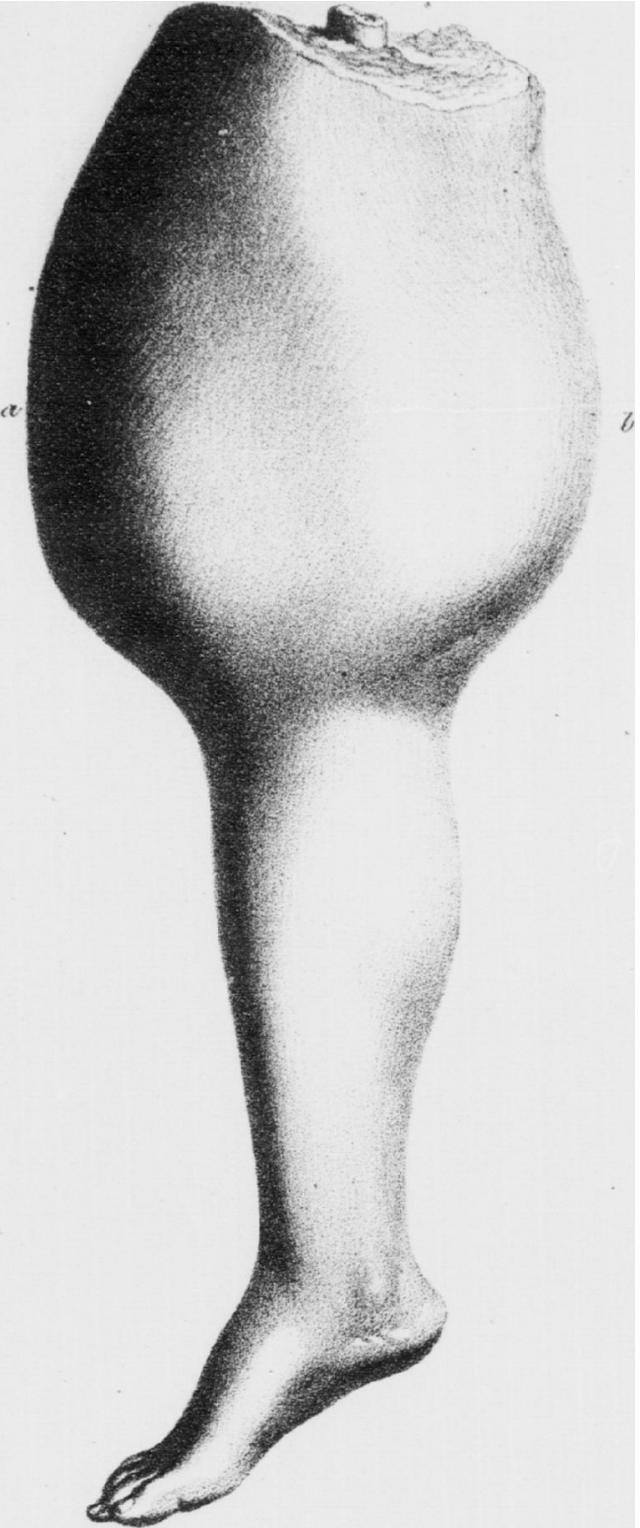

It lane ded listiburf luthoy

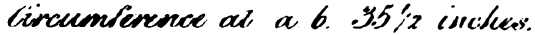

